\title{
Renata NascenteA GESTÃo PEDAGógICA dA AULA UNIVERSITÁRIA DA ÁREA DAS CIÊNCIAS NATURAIS E EXATAS
}

\author{
Marciele Taschetto da Silva ${ }^{1}$ \\ Adriana Moreira da Rocha ${ }^{2}$ \\ Silvia Maria de Aguiar Isaia ${ }^{3}$
}

\section{Resumo.}

Este estudo encontra-se inserido no contexto investigativo sobre formação de formadores e a gestão pedagógica da aula da área de Ciências Naturais e Exatas. Ressaltamos que a gestão pedagógica se constitui a medida que o professor se compromete com seu projeto de ensino, organizando e articulando saberes necessários para a formação de seus alunos e, consequentemente, para a sua própria formação. Desse modo, este trabalho tem como objetivo analisar definições teóricas e conceituais relevantes para [re]pensar a gestão pedagógica da aula e a formação docente e o reflexo desta na educação básica, em busca da qualidade do ensino na área de Ciências Naturais e Exatas. Em relação a esta temática sabemos que os docentes universitários possuem a responsabilidade e compromisso social com a ampla formação de futuros profissionais para além da mera transmissão de conhecimentos. Assim preocupa-nos refletir sobre a relação existente entre a gestão da aula dos docentes atuantes nos cursos de licenciatura e a formação ofertada aos futuros professores da educação básica. Esta relação apresenta certa dubiedade, pois ao mesmo tempo em que os professores realizam a gestão de suas aulas a fim de oferecerem uma boa formação para seus alunos, não são formados nem preparados para tal exercício. Desse modo, a gestão de sua aula é regida por saberes constituídos no seu cotidiano, decorrentes de esforços individuais, sob o prisma da pedagogia universitária.

Palavras-chave: Gestão pedagógica. Formação de formadores. Formação inicial.

\begin{abstract}
.
This is an investigative research in the area of teacher education and educational management in the field of Natural and Exact Sciences. It is emphasized that educational management is composed at the same time as the teachers are compromised with their teaching project, organizes and articulating the necessary knowledge for the student's formation and, consequently, for their own development. Thus, this study is a bibliographical research, aiming to examine relevant theoretical and conceptual definitions in order to (re)think educational management in initial teacher training, and its reflection within basic education, in pursuit of an education of quality in the field of Natural and Exact Sciences. In relation to this issue, it is known that college professors have the responsibility and social commitment to extensive training of future professionals that goes beyond the mere transmission of knowledge. Thus, it is a concern to reflect on the relationship between class management of professors in undergraduate courses and the training offered to prospective teachers of basic education. This

\footnotetext{
${ }^{1}$ Pedagoga, Especialista em Gestão Educacional e aluna do Curso de Mestrado do Programa de Pós-graduação da Universidade Federal de Santa Maria.

${ }^{2}$ Doutora em Educação, Professora do Centro de Educação e vice-coordenadora do Programa de Pósgraduação da Universidade Federal de Santa Maria, Pesquisadora do Grupo Kósmos.

${ }^{3}$ Doutora em Ciências Humanas. Professora do Programa de Pós-Graduação em Educação da UFSM, Coordenadora do Grupo de Pesquisa Trajetórias de Formação, membro da RIES - Rede Sulbrasileira de Investigadores da Educação Superior.
} 
relationship presents some ambiguity, due to the fact that at the same time that teachers perform the management of their classes in order to provide a good education for their students, they are not trained and prepared for such. Therefore, the management of their classes is governed by knowledge conventionalized in their daily life, arising from individual efforts, under the perspective of university pedagogy.

Keywords: Educational management. Teacher education. Initial education.

\section{Considerações iniciais}

O desenvolvimento deste trabalho justifica-se pela problemática da formação de professores universitários, uma vez que, os docentes dos cursos de licenciatura possuem o compromisso com a formação de professores que atuam ou atuarão no ensino básico. Contudo, diversos estudos evidenciam a falta de proximidade entre o contexto universitário e o escolar. Fato este possivelmente decorrente das próprias políticas de formação de professores, que acabam influenciando na postura ainda assumida pelos professores universitários, em que seguem o modelo de aula ultrapassado com a centralidade na transmissão de seus conhecimentos específicos (ZEICHNER, 2003). A gestão pedagógica da aula universitária compreende as dinâmicas desenvolvidas pelos professores no espaço-tempo da sala de aula em consonância com o projeto pedagógico institucional em prol da criação de um ambiente favorável para o desenvolvimento do ensino e aprendizagem efetiva (FERREIRA, 2008).

Desse modo, percebemos que a formação exigida pelos professores universitários na forma de lei é direcionada para os cursos de mestrado e doutorado, sendo que estes não formam para o ensino, mas possuem o foco na formação do pesquisador. Este trabalho tem como proposta refletir sobre a gestão da aula universitária, como atividade que caracteriza a identidade profissional docente e está diretamente ligada a formação dos professores do ensino básico. Assim, apresentamos como objetivo analisar definições teóricas e conceituais relevantes para repensarmos a formação docente e a repercussão desta na gestão pedagógica da aula universitária, em busca da excelência do ensino na área de Ciências Naturais e Exatas.

O presente trabalho se trata de uma contribuição teórica, em que buscamos discutir as interfaces que envolvem a gestão pedagógica da aula universitária, considerando a repercussão das políticas de formação e, consequentemente, também a formação inicial ofertada por estes nos Cursos de licenciaturas. 


\section{Gestão pedagógica da aula universitária}

A gestão, compreendida como tomada de decisão, organização, direção e participação (LÜCK, 2009) ocorre em todos os âmbitos das instituições educacionais. De acordo com Ferreira (2008, p. 08) a gestão se desenvolve "fundamentalmente na sala de aula, onde concretamente se objetiva o Projeto Politico Pedagógico não só como desenvolvimento do planejado, mas como fonte privilegiada de novos subsídios para novas tomadas de decisões". Para Libâneo (2004) a gestão, que está diretamente relacionada com os princípios de democratização e participação, implica na busca de objetivos comuns pela coordenação, o colegiado e demais profissionais da educação, onde cada um assume sua parte na execução de suas práticas para alcançarem um objetivo geral coletivo.

Apesar dos autores acima citados referirem-se à gestão pedagógica ligada à educação básica, no ensino superior as atribuições docentes não são diferentes. Todo curso de graduação possui seu Projeto Político Pedagógico de Curso, onde são explicitados os objetivos do curso, o papel que o professor deve assumir, bem como o perfil do aluno que se pretende formar relacionando com as áreas de atuação. Desse modo, cabe ao professor desenvolver o seu trabalho de acordo com o projeto defendido e almejado pelo curso. Nesta direção,
A gestão pedagógica, também, está ancorada nos saberes da docência que podem ser traduzidos pelo conhecimento aprofundado de um dado campo de estudos; pela produção e manejo de materiais didáticos; pelo domínio de instrumentos metodológicos; pela clareza quanto à opção epistemológica e quanto ao nível cognitivo e intelectual esperado dos alunos durante as situações de aprendizagem; pela criatividade e bom senso na elaboração de situações que desafiem o pensamento e que produzam a novidade; pela capacidade de organizar o planejamento das aulas, as atividades de aprendizagem e a avaliação dos alunos; e pelo espírito investigativo que permite a elaboração própria, o pensamento autônomo e a autoavaliação (LUNARDI, 2012, p. 96).

A gestão pedagógica se constrói à medida que o professor se compromete com seu projeto de ensino, organizando e articulando saberes necessários para a formação de seus alunos e, consequentemente, para a sua própria formação.

Assim, compreendemos a gestão pedagógica como o processo que envolve todos os âmbitos da docência, desde os saberes didáticos, visão social e compreensão das possibilidades e limitações de cada contexto, conhecimentos específicos da área, 
conhecimentos experienciais da profissão, produção dos conhecimentos, até a capacidade do professor de fazer a articulação de todos esses conhecimentos, direcionando-os ao ensino, que é o que caracteriza e dá sentido à profissão professor.

Oliveira (2013) ressalta que

O ensinar não é transferir conhecimento, pois demanda ao professor ter uma postura crítica, ter curiosidade, ter rigor metodológico para ensinar e fazer uma leitura de mundo, de forma crítica e ter criatividade para adequar o ensino às reais necessidades dos educandos, respeitando os seus saberes (p. 47).

Verificamos nas palavras de Oliveira, ainda que implicitamente, a importância da competência pedagógica como centro do processo da gestão da sala de aula, uma vez que ensinar requer a capacidade de atuar nos cenários educativos de forma crítico-reflexiva, não se restringindo ao domínio do conteúdo, às habilidades de ensino e aspectos administrativos, mas envolvendo um processo de reflexão permanente sobre o processo de ensino e aprendizagem, contribuindo para o próprio desenvolvimento profissional.

Nesta mesma direção, Bolzan e Isaia (2006) afirmam que o papel do professor vai além do domínio da área de conhecimento, pois este exercício perpassa pelo menos três dimensões: o conhecimento científico, o conhecimento pedagógico compartilhado e o conhecimento profissional. Sendo assim,

[...] é preciso considerar que a prática educativa do professor implica em possibilitar a passagem do conhecimento científico para o conhecimento acadêmico e deste para o profissional, ou seja, o exercício da transposição didática no ato educativo. (2006, p. 494).

É essencial que o docente domine os conhecimentos de sua área específica de formação, porém precisa ter consciência da importância da dimensão pedagógica para a transposição de seu conhecimento. Esta envolve formas de conceber e desenvolver o ensino, proporcionando ao professor refletir sobre a sua prática, percebendo-se como mediador do processo de aprendizagem. A dimensão pedagógica oferece suportes para que ocorra uma interlocução entre a dimensão do conhecimento específico e a dimensão do conhecimento profissional, pois integra tanto o saber e o saber-fazer de determinada profissão.

Dessa forma, apesar da importância da dimensão pedagógica, os estudos que vem sendo realizados ao longo dos tempos, apresentam indicadores de que as dificuldades 
apresentadas pela maioria dos professores estão relacionadas ao fato de que a formação do professor universitário não contempla esta dimensão. Este indicador aponta certa redundância, pois ao mesmo tempo em que estes docentes não foram preparados para o exercício de sua profissão, se espera deles a responsabilidade de preparar futuros educadores.

\section{Pedagogia universitária das ciências naturais e exatas}

Quando discutimos as práticas organizacionais do trabalho docente, nos remetemos à pedagogia universitária. Esta trata-se de um campo em construção, que tem seus pilares tramados às características próprias das práticas em sala de aula, decorrentes da aprendizagem docente. Para maior compreensão, apresentamos a definição de Cunha para o termo:

A pedagogia universitária é um campo polissêmico de produção e aplicação dos conhecimentos pedagógicos na educação superior. Reconhece distintos campos científicos dos quais toma referentes epistemológicos e culturais para definir suas bases de características. Pressupõe, especialmente, conhecimentos no âmbito do currículo e da prática pedagógica que incluem as formas de ensinar e de aprender. Incide sobre as teorias e as práticas de formação de professores e dos estudantes da educação superior. (CUNHA, 2004, p. 321)

Compreender a importância da pedagogia universitária significa reconhecer a especificidade do cenário universitário e a peculiaridade da formação de cada docente. É importante ressaltarmos a inexistência de um curso com o foco específico para a formação dos formadores, fato este que contribui para que a construção da profissão ocorra através de esforços individuais, sucedendo assim com características diversificadas. A preocupação com a problemática da formação docente também é demonstrada por Maciel (2009):

Um detalhamento maior desta realidade me leva a indagação: Se os cursos de graduação não formam docentes para o ensino superior, mas sim para a educação infantil, ensino fundamental e ensino médio e, ainda se os cursos de pós-graduação estão voltados, prioritariamente para áreas específicas de interesse de pesquisa científica, quem forma o docente para o ensino superior? (MACIEL, 2009, p. 64). 
Como sinaliza Maciel, a falta de formação para o ensino superior demonstra a desvalorização da profissão, tendo como agravante o contexto das licenciaturas. Evidenciamos este fato nas próprias diretrizes específicas dos cursos da área das ciências exatas e da terra, contexto deste estudo. No que tange ao perfil desejado, competências e habilidades dos formandos, é presente a valorização dos conhecimentos específicos da área sobrepostos aos conhecimentos pedagógicos. Ferreira et al.(2014) ao discutir a formação de professores, destaca como dado de suas pesquisas, que as maiores dificuldades apresentadas pelos docentes estão relacionadas ao ensino da área das ciências naturais e exatas, por se tratarem de cursos objetivos e com alto grau de concentração na linguagem e conteúdos específicos da área. Nesta mesma perspectiva Almeida, Bastos e Mayer (2001) afirmam que

a imagem de ciência mantida pela sociedade está centrada nesta visão cartesiana e é fortemente impregnada pelo positivismo, embora não tenhamos consciência deste fato. Esta imagem também mantida pelos professores influencia suas ações em sala de aula, levando-os a uma série de atitudes, como, por exemplo, a privilegiar o conhecimento científico, em detrimento do conhecimento culturalmente desenvolvido, devido ao status conferido ao primeiro por envolver a razão na sua construção; a estimular uma atitude passiva de aceitação sem questionamento das teorias científicas, consideradas como verdadeiras, enfatizando sua memorização, para evitar possíveis deturpações causadas pelas interpretações dos alunos; a desvalorizar a aplicação das ideias científicas em situações reais, de acordo com a visão de que a teoria é superior à prática, estando o poder nas mãos de quem domina a teoria. (p.02).

Apesar dos estudos realizados por Almeida, Bastos e Mayer (2001) e Ferreira et al.(2014), tendo como foco a formação de professores e os processos de ensino não focando especificamente no contexto universitário, compreendemos que representam dados relevantes para caracterizarmos a pedagogia universitária na área das ciências naturais e exatas, pois apresentam peculiaridades inerentes à área, que ao nosso entendimento se constituem desde o contexto da formação inicial. Tais como a transmissão de conteúdos, o ensino cartesiano e o ensino centralizado no conhecimento específico e em uma linguagem especialista da área de conhecimento. Ferreira et al. (2014) ainda apresentam uma análise sobre a possível solução da problemática apresentada, destacando a importância de uma formação mais ampla e que valorize os conhecimentos pedagógicos: 
Considerando aqui as exatas, um licenciado em matemática, por exemplo. Sabemos que em nossos dias o necessário não é só saber matemática para ser um bom professor, mas o fundamental é, além de saber matemática, saber como aplicá-la para que haja maior compreensão, apreensão dos conteúdos matemáticos por parte dos alunos. É preciso, saber trabalhar com as novas metodologias, ter conhecimento e entender o momento para introduzi-las em sua prática e qual delas poderia estar relacionando com a sua aplicação em sala de aula. (FERREIRA et al., 2014, p. 230).

Desse modo, consideramos que o exercício docente possui inúmeros desafios, ao iniciar pela inexistência de uma formação específica e ao que se refere à área das ciências naturais e exatas, existem ainda desafios vinculados a organização estrutural dos currículos da área, de modo que privilegiam o estudo de conceitos, linguagem e metodologias, tornando as aprendizagens pouco eficientes para interpretação e intervenção na realidade (BORGES e LIMA, 2007). Assim, compreendemos que a docência superior implica formar-se na e para a prática da sala de aula, pois segundo Bolzan e Isaia (2010, p. 16) "não podemos falar em aprendizagem docente sem referencia aos discentes e seus processos formativos, pois, à medida que os professores são formadores, também se formam”. De acordo com Tardif (2002), a existência dos professores universitários enquanto categoria profissional depende da capacidade de domínio e mobilização de um conjunto de saberes relacionados à consciência do ato exercido, ou seja, da justificativa consciente dos sujeitos pelas suas ações em sala de aula.

Em outras palavras, Isaia e Bolzan (2009) também ressalvam a relevância dos saberes específicos da docência:

Considerar a especificidade própria a docência implica mais do que o domínio das áreas específicas, exige do professor a compreensão genuína dos conhecimentos, saberes, destrezas e competências referentes à sua profissão [...]. (ISAIA e BOLZAN, 2009, p. 140).

Nesse sentido, o exercício da docência é um aprendizado permanente, é processo e, portanto, movimento em que o docente se faz e se refaz no cotidiano de seu trabalho. Assim, destacamos a sala de aula universitária, independente da área de formação/atuação, como núcleo da aprendizagem docente e, consequentemente da construção de uma pedagogia universitária específica de cada contexto. 
O processo de aprendizagem docente coloca o professor diante do desafio de construir formas de apropriação de estratégias capazes de favorecer o domínio de conhecimentos específicos articulando-os com a dimensão pedagógica (ISAIA e BOLZAN, 2009, p. 138).

Embora exista o consenso entre diversos autores (PIMENTA e ANASTASIOU, 2002; TARDIF, 2002; MASETTO, 2003; GRILLO e GESSINGER, 2008; ISAIA e BOLZAN, 2009) de que a profissão docente deve ser respaldada por saberes que valorizem o ensino, é necessário o reconhecimento também, de que cada área de formação possui especificidades que precisam ser valorizadas, refletidas e aprofundadas como estudo. Pois estas representam o delineamento de formas próprias de conduzir o processo de ensino.

\section{Salientamos que}

A aprendizagem docente constitui-se como elemento basilar da pedagogia universitária, na medida em que se consolida a partir da articulação entre modos de ensinar e de aprender, permitindo aos atores desse processo intercambiarem essas funções, tendo o conhecimento profissional compartilhado e a aprendizagem colaborativa como condição para o desenvolvimento e concretização do fazer-se professor ao longo da trajetória pessoal e profissional. (BOLZAN e ISAIA, 2010, p. 15).

Estas reflexões nos direcionamos aos estudos de Marcelo García (1999) que demonstram que a aprendizagem docente só ocorre no momento em que há uma interrelação entre a autoformação, hetero e interformação, pois é necessário que o sujeito reconheça a importância de se aperfeiçoar enquanto profissional. Assim, Marcelo García (1999) parte do princípio de que os processos formativos são apenas realmente efetivos quando principiam internamente, quando o sujeito toma consciência da necessidade de sua própria formação. Nenhum curso e/ou experiência de vida serão significativas aos sujeitos se estes não possuem vontade e nem comprometimento com sua autoformação, nada será [trans] formado, uma vez que "ninguém pode formar o outro, se este não quiser formar-se [...].” (ISAIA e BOLZAN, 2009, p. 125).

Desse modo, compreendemos que a pedagogia universitária ocorre através das práticas resultantes da aprendizagem de cada sujeito, que somadas constituem características peculiares às áreas de formação e atuação dos docentes. 


\section{A formação do formador e a repercussão nos cursos de licenciaturas}

Ao buscarmos discorrer sobre a formação dos formadores, ressaltamos que partimos do pressuposto de que a qualidade da educação básica é consequência do trabalho que vem sendo desenvolvido nas universidades. Pois concordamos que "os desafios do mundo contemporâneo, particularmente os relativos às transformações que a educação escolar precisa passar, incidem diretamente nos cursos de formação inicial" (DELIZOICOV; ANGOTTI e PERNAMBUCO, 2007, p. 31) Desse modo, ao discutirmos a docência universitária, sinalizamos a importância de discorrermos sobre a formação ofertada nos Cursos de licenciaturas, uma vez que a docência superior é uma atividade que envolve uma multiplicidade de saberes e funções, que se revertem na formação de futuros profissionais.

A complexidade que permeia e constitui a docência superior vem despertando o interesse de diversos pesquisadores sobre o tema (MARCELO GARCIA, 1999; PIMENTA e ANASTASIOU, 2002; MASETTO, 2003; ISAIA e BOLZAN, 2006, 2009; MACIEL, 2009; BOLZAN e ISAIA, 2010), sinalizando uma crescente preocupação com a inexistência de uma formação específica para este exercício.

De acordo com Isaia (2006) o verbete docência universitária compreende atividades desenvolvidas pelos professores, orientadas para a preparação de futuros profissionais. Nesse sentido, compreendemos a importância do desenvolvimento de certas destrezas pelo professor, a fim de que sejam capazes de articular a teoria de sua área de domínio específico, os conhecimentos profissionais e pedagógicos.

A Lei de Diretrizes e Bases da Educação 9394/96 é bastante superficial ao que se refere à atividade docente, explicitando como requisito para o exercício da docência superior a preparação (não a formação) nos cursos de mestrado e doutorado, mas sem exigência da obrigatoriedade, estabelecendo como parâmetro a quantidade de no mínimo $30 \%$ dos docentes com esta titulação em cada instituição:

A preparação para o exercício do magistério superior far-se-á em nível de pós-graduação, prioritariamente em programas de mestrado e doutorado. Parágrafo único: O notório saber, reconhecido por universidade com curso de doutorado em área afim, poderá suprir a exigência de título acadêmico (LDBEN, art. 66). 
A própria Lei sinaliza a desvalorização da profissão docente, pois os cursos stricto sensu enfatizam a pesquisa e não a docência. Sendo assim, a entrada em uma $\operatorname{IES}^{4}$ e a progressão da carreira estão relacionados à titulação e a produção científica. Desta forma, os docentes na universidade acabam focando seu trabalho mais para a pesquisa do que para o ensino, centrando-se em sua área de conhecimento específico, como se este domínio bastasse para o exercício da docência.

Estudos realizados por Anastasiou e Pimenta (2002) apontam a importância da formação pedagógica, mas infelizmente identificam que há quase um consenso geral por parte de professores de que a docência superior não requer formação no campo do ensino/aprendizagem. As autoras ainda afirmam que para eles,

[...] seria suficiente o domínio de conhecimentos específicos, pois o que identifica a docência [grifo nosso] é a pesquisa e/ou o exercício profissional no campo. Mesmo porque, diz o dito popular, "quem sabe faz" e "quem não sabe ensina". Nesse conceito, o professor é aquele que ensina, isto é, dispõe os conhecimentos aos alunos. Se estes aprendem ou não, não é problema do professor, especialmente do universitário, que muitas vezes está ali como uma concessão, como um favor, como uma forma de complementar o salário, como um abnegado que vê no ensino uma forma de ajudar os outros, como bico, etc.

$\mathrm{Na}$ maioria das instituições de ensino superior, incluindo as universidades, embora seus professores possuam experiência significativa e mesmo anos de estudo em suas áreas específicas, predomina o despreparo e até um desconhecimento científico do que seja o processo de ensino e aprendizagem, pelo qual passam a ser responsáveis a partir do instante em que ingressam na sala de aula (2002, p. 36-37).

Todo professor é gestor de sua prática pedagógica, portanto, responsável pela mobilização de saberes necessários para intervir nos processos de ensino e aprendizagem. Sendo assim, destacamos a importância do reconhecimento da docência como profissão e, não apenas como "complemento" às atividades profissionais liberais e de pesquisa. Sem este reconhecimento, jamais será conquistada uma formação docente de qualidade, pois, de acordo com Marcelo García (1999) se não há interesse do sujeito por uma autoformação, a heteroformação e a interformação não ocorrerão.

A questão não é desconsiderarmos a formação ofertada nos cursos de pósgraduação stricto sensu, pois reconhecemos a importância do professor como pesquisador

\footnotetext{
${ }^{4}$ Instituição de Ensino Superior.
} 
de sua própria prática. No entanto, preocupa-nos o perigo da dicotomia que vem ocorrendo nas instituições de ensino superior, entre o ensino e a pesquisa, onde o trabalho docente é fundamentalmente identificado com a atividade de pesquisa, considerando esta a sua principal fonte de prestígio acadêmico e valorização profissional (BAZZO, 2008). É preciso que haja esforços institucionais para uma valorização da formação docente, para além da pesquisa, mas que enfoque o profissional que orienta, acolhe, que ensina, educa, conversa, compartilha, que reconhece as possibilidades de cada contexto, que avalia sua própria aprendizagem, sendo um gestor pedagógico do seu fazer.

De qualquer modo, a forma como o docente universitário irá assumir a gestão de sua aula, certamente influenciará no modo como seus alunos procederão posteriormente em suas futuras atuações. A profissão docente possui uma especificidade única que a difere das demais profissões, que é o fato de que o professor aprende a profissão em um lugar similar àquele em que vai atuar, isso se traduz na teoria da simetria invertida. De acordo com a Resolução CNE/CP1, de 18 de fevereiro de 2002, que institui as Diretrizes Curriculares para a Formação de Professores, em seu Artigo $3^{\circ}$, inciso II, a formação oferecida deve corresponder a formação esperada pelo futuro profissional, havendo harmonia entre a situação de formação e atuação. De acordo com Thomé; Stecanella e Bueno Krahe:

O conceito de simetria invertida ressalta que o professor em sua formação em atuação profissional "no sentido em que é vivendo o papel de aluno que ele aprende a ser professor", e assim ele vai se enxergando através do outro. Esse aluno/professor deverá vivenciar e fazer reflexões constante sobre as situações vividas, ou seja vai refletindo sobre o aprender-ensinar-aprender. (2007, p. 08).

A simetria invertida é um processo muito interessante, pois resgata a reflexão do vivido, e a repetição de posturas, metodologias em situações que deram certo, ou mesmo contribuem na busca do aprimoramento das práticas docentes. Assim, podemos dizer que muito do que o docente faz em sala de aula é resquício da formação que teve ou durante o ensino básico ou durante a graduação e/ou pós-graduação.

Grande parte das ações que se têm em sala de aula é fruto da tradição, da experiência prévia como aluno, a qual leva a imitar às vezes até sem perceber, as atitudes dos professores com que se estudou ao longo da vida. Até mesmo os portadores de discurso em favor da tendência construtivista são, muitas vezes, "atropelados" pelo ensino tradicional, discursivo, centrado no 
sujeito que ensina, a sujeitos que aprendem "a partir do nada". (DELIZOICOV; ANGOTTI e PERNAMBUCO, 2007, p. 124).

$\mathrm{Na}$ contramão desta postura, cabe aos docentes universitários "assumirem-se como parte importante e pró-activa da construção do futuro e modificar essas práticas, de acordo com o seu projeto de ensino. É nesta perspectiva que situamos também a responsabilidade das instituições pelo aumento da qualidade pedagógica" (ESTEVES, 2008, p. 104).

Em relação à formação e a atuação dos professores de diversos níveis de ensino da área de Ciências, os autores Chassot (2003) e Delizoicov; Angotti e Pernambuco (2007) fazem uma crítica com respeito a ausência de uma formação crítica e que dê conta da compreensão por parte do aluno dos fenômenos científicos que permeiam o mundo natural. Chassot (2003) defende o que ele denomina de alfabetização científica, que deveria ocorrer em todos os níveis educacionais, que trata da aquisição de uma linguagem científica por todos, e que auxiliaria na compreensão e na busca de melhorias sobre os fenômenos que nos rodeiam. Já Delizoicov; Angotti e Pernambuco (2007) além de defenderem uma formação crítica, também discutem sobre os métodos de ensinar ciências, sinalizando uma necessária mudança.

[...] lamentavelmente, nem sequer na maioria dos Cursos de formação inicial em licenciatura essas perspectivas, tanto dos novos materiais didáticos como dos resultados de pesquisa, são consideradas. A formação de professores, na maioria dos cursos, ainda está mais próxima dos anos 1970 do que de hoje. (DELIZOICOV; ANGOTTI e PERNAMBUCO, 2007, p. 41).

A estudiosa Esteves (2008) também defende a formação crítica dos acadêmicos, trazendo como papel dos professores universitários:

Facilitar e sustentar a emergência de capacidades dos estudantes para pensarem criticamente, para serem capazes de se autodeterminarem e continuarem a aprender ao longo da vida têm vindo a ser apontadas como as tarefas centrais da ação docente. A dificuldade (e a controvérsia) estará em como proceder para concretizar tais intenções. (p. 106).

Desse modo, entendemos que ao mesmo tempo em que a prática dos docentes universitários possui resquícios de modelos de professores que tiveram durante a vida escolar e acadêmica, é necessário refletir sobre as novas demandas e sua responsabilidade como formador de profissionais que deverão contribuir para qualificar o sistema de ensino 
basico. Assim como, cabe aos docentes universitários assumir uma postura dinâmica, com a perspectiva de formação crítica, questionando os métodos e tendo como norte de sua prática um objetivo claro e correspondente ao seu tempo/contexto histórico-social.

Nessa perspectiva, Esteves (2008) nos apresenta conceitos que traduzem o que ela denomina de excelência pedagógica:

(i) questionar os fins desse próprio ensino, antes de questionar os meios; (ii) questionar as políticas globais, regionais, nacionais de ensino superior e ciência, antes de questionar o modo como as comunidades de aprendizagem se organizam em cada instituição, em cada curso e em cada unidade curricular; (iii) questionar a sociedade e o que ela espera (e não espera) do ensino superior, antes de avaliar se tal encomenda está a ser satisfeita ou não. (ESTEVES, 2008, p. 102).

Percebemos que a excelência pedagógica vai ao encontro do conceito da palavra gestão, que representa o conceito de participação, coletividade, colaboração e transparência. Ou seja, a gestão da aula do professor universitário se dá em um contexto histórico/social, em determinado espaço/tempo, que deve ter consonância com um projeto institucional, bem como os documentos que traduzem as demandas da sociedade. Sendo assim, a gestão da aula não é um ato isolado, mas é norteado por objetivos pensados no e para o coletivo.

Ressaltamos no que diz respeito a primeira ideia apresentada pela autora, quando menciona a importância de sempre se questionar os fins para pensar os meios, ou seja, mais do que mudanças de estratégias, toda prática deve ser norteada por objetivos concretos. Concordando com isso, Delizoicov; Angotti e Pernambuco (2007) nos dizem que

Se é consensual e inquestionável que o professor de Ciências Naturais, ou de alguma das ciências, precisa ter o domínio de teorias cientificas e de suas vinculações com as tecnologias, fica cada vez mais claro, para uma quantidade crescente de educadores, que essa característica é necessária, mas não suficiente, para um desempenho docente. A atuação profissional dos professores das Ciências no ensino fundamental e médio, do mesmo modo que a de seus formadores, constitui um conjunto de saberes e práticas que não se reduzem a um competente domínio dos procedimentos, conceituações, modelos e teorias científicos. (p. 31-32) 
Os materiais didáticos e tecnológicos, por exemplo, são importantes estratégias para o ensino, mas de nada servirão se persistir na gestão da aula a dissociabilidade e a centralização por parte do professor no processo de ensino e não de aprendizagem. Desse modo, a nova postura que deve ser assumida pelos professores formadores e formandos deve ultrapassar a mera transmissão dos conteúdos, descrita por Delizoicov; Angotti e Pernambuco (2007) como senso comum pedagógico e investir no que Chassot (2003) denomina de alfabetização científica.

[...] comprometidos com a superação do que tem sido denominado como senso comum pedagógico, impregnado no ensino/aprendizagem dessa área, a que todos estamos perigosamente sujeitos. Esse risco está relacionado, entre outros, com o pressuposto de que a apropriação de conhecimentos ocorre pela mera transmissão mecânica de informações. [...] atividades de ensino que só reforçam o distanciamento do uso de modelos e teorias para a compreensão dos fenômenos naturais e daqueles oriundos das transformações humana, além de caracterizar a ciência como produto acabado e inquestionável: um trabalho didático-pedagógico que favorece a indesejável ciência morta. (DELIZOICOV, ANGOTTI e PERNAMBUCO, 2007, p. 32-33).

Corroborando com isso, Chassot (2003) apresenta como preocupação em seus estudos a importância de compreendermos não só as Ciências Naturais e Exatas, mas todas as ciências como linguagens situadas em um tempo/espaço e nos colocarmos como sujeitos conhecedores e críticos.

Há nessa dimensão a busca de se investigar um ensino mais impregnado com posturas mais holísticas- isto é, com um ensino de ciências que contemple aspectos históricos, dimensões ambientais, posturas éticas e políticas, mergulhadas na procura de saberes populares e nas dimensões das etnociências -, proposta que traz vantagens para uma alfabetização científica mais significativa, como também confere dimensões privilegiadas para a formação de professoras e professores. (p. 97).

Desse modo, para se alcançar a excelência pedagógica na gestão da aula e, consequentemente na formação dos futuros educadores, Pereira; Pereira e Carrão (2008) nos afirmam que

Não se pode conceber na atualidade que o profissional da educação exerça a função docente sem a devida formação profissional. Esta inclui, além do domínio dos conteúdos básicos, 
específicos oferecidos pelos cursos de graduação a formação pedagógica para que o professor considere o aspecto técnico, instrumental na organização do ensino, e mais ainda, a dimensão política do ato pedagógico. Isso implica que o professor saiba o porque e o para que fazer de sua ação docente. (p. 02).

Desse modo, ao discutirmos sobre a formação do formador e a excelência da formação dos futuros professores da educação básica, temos que considerar a complexidade do contexto social, político, institucional e global. Uma vez que, a gestão do professor universitário se dá norteada por diversos documentos legais, como as diretrizes, suas resoluções, os PPC's, etc., mas em momento algum é previsto em forma de lei a formação específica para a atuação no magistério superior. O que temos são cursos de mestrado e doutorado que formam para a pesquisa e o ingresso na carreira e as cobranças institucionais se dão neste parâmetro.

E o complexo se agrava, quando estes docentes, sem nenhuma experiência profissional na educação básica, são responsabilizados por formar professores que atuarão neste contexto. Sendo assim, a excelência pedagógica fica dependente de esforços individuais de cada sujeito, a medida que este se compromete com sua prática e vai adquirindo experiências formativa e profissional. Sendo assim, aos professores um curso de formação de professores cabe o compromisso de oferecer a devida instrumentalização técnica e política a seus alunos; conteúdos que forneçam o embasamento necessário ao professor para facilitar o processo de aprendizagem do aluno (PEREIRA, et al., 2008).

Com vista a necessidade da melhoria e do engajamento institucional com a formação de seus formadores, cabe ainda ressaltarmos que o requisito indispensável a uma prática comprometida do professor formador e formando é a consciência de que a gestão pedagógica é uma prática situada, historicizada contextualizada e, portanto, devendo ter consonância com a realidade do contexto do país.

\section{CONSIDERAÇÕES FINAIS}

A luz dos estudos realizados sobre o tema gestão pedagógica da aula universitária focada na formação dos formadores e a repercussão nos cursos de licenciatura, cabe neste momento retomar elementos marcantes encontrados neste estudo, bem como [re]pensar a temática, em busca da qualidade do ensino na área de ciências naturais e exatas.

Inicialmente, consideramos de grande valia destacarmos a desvalorização do trabalho docente em sala de aula encontrada em diversos estudos (PIMENTA e ANASTASIOU, 2002; MASETTO, 2003; ISAIA e BOLZAN, 2006, 2009; MACIEL, 
2009; BOLZAN e ISAIA, 2010). Desvalorização esta, também pelo fato da ausência de uma formação para o ensino superior, em que o ingresso na carreira docente, bem como as cobranças institucionais estão relacionados à incessante produção científica, ficando o ensino como pano de fundo.

A ausência de uma formação específica para o ensino superior acaba repercutindo em sentimento de insegurança, fazendo com que o docente acabe realizando a gestão de sua aula respaldada em modelos de professores que tiveram durante a educação básica ou no ensino superior. Considerando que estes modelos de aulas e de professores faziam parte de períodos e contextos bem diferente do que nos encontramos atualmente, provavelmente marcados por um período em que o professor era o centro do processo e a ele cabia a transmissão dos conteúdos.

Ao que tange especificamente à área das ciências naturais e exatas, os autores Ferreira et al. (2014), Almeida, Bastos e Mayer (2001), Delizoicov, Angotti e Pernambuco (2007) e Chassot (2003) apontam que a área é marcada pela centralidade na transmissão dos conteúdos específicos, sem a preocupação com a experimentação e compreensão como ciência em movimento, mas apenas com a aquisição desta como verdade absoluta, a chamada ciência morta.

Destacamos ainda, outras especificidades marcantes da área das ciências naturais e exatas, apresentadas por Ferreira et al. (2014) como dados de suas pesquisas. A primeira delas refere-se ao fato de que as maiores dificuldades apresentadas pelos docentes estão relacionadas ao ensino da área das ciências naturais e exatas, por se tratarem de cursos objetivos e com alto grau de concentração na linguagem e conteúdos específicos da área, organização estrutural dos currículos da área, de modo que privilegiam o estudo de conceitos, linguagem e metodologias, tornando as aprendizagens pouco eficientes para interpretação e intervenção na realidade.

Diante destas colocações, não podemos responsabilizar apenas os professores pelo cenário formativo, pois sem um incentivo ou mesmo sem respaldo consistente não é possível realizar grandes transformações. É imprescindível que o poder público a e as Instituições de Educação Superior assumam a sua parte e reconheçam a complexidade da docência, sendo referentes de uma necessária ruptura cultural e cidadã.

Desta forma, finalizamos este estudo sinalizando a necessidade de investimentos e pesquisas que nos conduzam ao aprofundamento da complexidade que envolve a gestão pedagógica dos formadores de professores, bem como, estudos que destaquem as 
necessidades e experiências dos próprios formadores e formandos sobre suas práticas formativas.

\section{REFERÊNCIAS}

ALMEIDA, M. A. V. de.; BASTOS, H. F. N.; MEYER, M. Entre o sonho e a realidade: comparando concepções de professores de $1^{\mathrm{a}}$ a $4^{\mathrm{a}}$ séries sobre ensino de ciências com a proposta dos PCNS. In: $3^{\circ}$ ENCONTRO NACIONAL DE PESQUISA EM EDUCAÇÃO EM CIÊNCIAS, 2001, Atibaia/São Paulo. 2001. Disponível em: <http://www.nutes.ufrj.br/abrapec/iiienpec/Atas\%20em\%20html/o62.htm>. Acesso em 03 jun. 2014.

BAZZO, V. L. Constituição da profissionalidade docente na educação superior: apontamentos para uma política nacional de formação. In: $31^{a}$ Reunião anual da ANPED, 2008, Caxambu/MG. 2008.

BOLZAN, D. P. V.; ISAIA, S. M. A. Pedagogia Universitária e Aprendizagem Docente: Relações e novos sentidos da professoralidade. Revista Diálogo Educacional. Curitiba, v. 10, N²9, p. 13-26, jan./abr. 2010.

BORGES, R. M. R.; LIMA, V. M. do R. Tendências contemporâneas do ensino de Biologia no Brasil. In: Revista Electrónica de Enseñanza de las Ciências, v. 6, n. 1, 2007.

BRASIL. Ministério da Educação e do Desporto Secretaria de Educação Fundamental. Lei n ${ }^{\circ}$ 9394/96. LDB - Lei de Diretrizes e Bases da Educação Nacional. 1996. Disponível em: <www.mec.gov.br>. Acesso em: 15 de nov. de 2013.

Resolução CNE/CP n. 1, de 18 de fevereiro de 2002. Institui Diretrizes Curriculares Nacionais para a Formação de Professores da Educação Básica, em nível superior, curso de licenciatura, de graduação plena. Diário Oficial da União, Brasília, DF, 18 fev. 2014.

Resolução CNE/CP n. 2/2002, de 19 de fevereiro de 2002. Institui a duração e a carga horária dos cursos de licenciatura, de graduação plena, de formação de professores da Educação Básica em nível superior. Diário Oficial da União, Brasília, DF, 15 nov. 2013.

Parecer CNE/CP 09, 08 de Maio de 2001. Diretrizes Curriculares Nacionais para a Formação de Professores da Educação Básica, em nível superior, curso de licenciatura, de graduação plena. Brasília/DF/BRA: Diário Oficial da União, 18 Jan. 2002, Seção 1, p.31. 2001b. Disponível em: <http://portal.mec.gov.br/cne/ arquivos/pdf/009.pdf >. Acesso em: 18 Fev. 2014.

CHASSOT, A. Alfabetização científica: uma possibilidade para a inclusão social. In: Revista Brasileira de Educação. n. 22, p. 89-100, Jan/Abr, 2003. 
COSTA, F. F. Formação inicial de professores: novas políticas para velhas práticas. In: IX ANPED SUL - Seminário de Pesquisa da Região Sul. Anais. Caxias do Sul: RS, UCS, 2012.

CUNHA, M. I. da. Diferentes Olhares Sobre as Práticas Pedagógicas no Ensino Superior: a docência e sua formação. Educação. Porto Alegre, ano XXVII, v. 54, n. 3, p. 525536,set./dez. 2004.

DELIZOICOV, D.; ANGOTTI, J. A.; PERNAMBUCO, M. M. Ensino de Ciências: Fundamentos e métodos. $2^{\text {a }}$ ed. São Paulo: Cortez, 2007.

ESTEVES, M. Para a excelência pedagógica do ensino superior. In: Revista de ciências da educação. Centro Universitário Salesiano de São Paulo. São Paulo: SP. n.7, p. 101110, Jul./Dez. 2008.

FERREIRA, L. S. Gestão do pedagógico: de qual pedagógico se fala? In: Currículo sem Fronteiras. Universidade Federal de Pelotas. Pelotas: RS. v.8, n.2, p.176-189, Jul./Dez. 2008.

Professoras e professores como autores de sua professoralidade: a gestão do pedagógico na sala de aula. RBPAE. Universidade Federal do Rio Grande do Sul. Porto Alegre: RS. v.25, n.3, p. 425-438, set./dez. 2009.

FERREIRA, L. G.; FERREIRA, L. G.; FERREIRA, A. G. Fazer Docente: reflexões em torno da formação, do trabalho e das especificidades da área de atuação docente. In: LOPES, A.; CAVAlCANTE, M. A. da S.; OllVEIRA, D. A.; Hypólito, A. M. (Orgs.). Trabalho Docente e Formação: Políticas, Práticas e Investigação: Pontes para a mudança. Porto/Portugal. Edição: FPCUPE, p. 224-232, Jan. 2014. Disponível em: $<$ http://www.fpce.up.pt/trabalhodocenteformacao/>

GRILLO, M. C.; GESSINGER, R. M. Constituição da identidade professional, saberes docentes e prática reflexiva. In: GRILLO; FREITAS; GESSINGER; LIMA (Orgs) $A$ gestão da aula universitária na PUCRS. Porto Alegre: EDIPUCRS, 2008, p. 35-42.

HOUAIS. A. Dicionário Houaiss da Língua Portuguesa. 2011. Disponível em: <http://biblioteca.uol.com.br/ > Acesso em: 09 out. 2013

ISAIA, S.; BOLZAN, D.P.V. Aprendizagem docente na educação superior: Construções e tessituras da professoralidade. Educação. Porto Alegre, 2006.

Construção da profissão docente/professoralidade em debate: desafios para educação superior. In: XIII ENCONTRO NACIONAL DE DIDÁTICA E PRÁTICA DE ENSINO- ENDIPE. Recife, Universidade Federal de Pernambuco, 2006b.

(Orgs.) Pedagogia Universitária e desenvolvimento profissional docente. Porto Alegre: EDIPU:CRS, 2009.

KRAHE, Elizabeth D. Reforma curricular de Licenciaturas. UFRGS (Brasil) - UMCE (Chile) - Década de 1990. Porto Alegre: Editora UFRGS, 2008. 
LIBÂNEO, J. C. O ensino de graduação na universidade: a aula universitária. (2000). Disponível em www.ucg.br/site_docente/edu/libaneo/pdf/ensino/pdf. Acesso em $12 / 09 / 2013$.

LIBÂNEO, J. C.; PIMENTA, S. G. Formação de profissionais da educação: visão crítica e perspectiva de mudança. In: Educação \& Sociedade. Campinas, v. 20, n. 68, p. 239277, dez. 1999.

LÜCK, H. Dimensões da gestão escolar e suas competências. São Paulo: Fundação Lemann. Editora: Positivo, 2009.

LUNARDI, E. M. Qualidade da gestão pedagógica no curso de pedagogia. 2012. 262f. Tese (Doutorado em Educação). Pontifícia Universidade Católica do Rio Grande do Sul. Porto Alegre: RS. 2012.

MACIEL, A. M. R.. O processo formativo do professor no ensino superior: em busca de uma ambiência (trans)formativa. In: ISAIA, Sílvia Maria de Aguiar; BOLZAN, Dóris Pires Vargas; MACIEL, Adriana Moreira da Rocha. (Orgs). Pedagogia universitária: tecendo redes sobre a educação superior Santa Maria: Editora da UFSM, pp.63-77, 2009

MARCELO GARCÍA, C. Formação de Professores: para uma mudança educativa. Porto, Portugal: Porto Ed., 1999.

MASETTO, M. T. Competência pedagógica do professor universitário. São Paulo: Summus, 2003.

OLIVEIRA, M. M. Sequencia didática interativa no processo de formação de professores. Petrópolis: RJ: Vozes, 2013.

PIMENTA, S. G.; ANASTASIOU, L. G. C. Docência no Ensino Superior. São Paulo: Cortez, 2002.

TARDIF, M. Saberes docentes e formação profissional. Petrópolis, RJ: Vozes, 2002.

THOMÉ, R.; STECANELA, N.; BUENO KRAHE, I. A prática pedagógica do espelho. In: VII Seminário Escola e Pesquisa um Encontro Possível; 2007, Caxias do Sul/RS: UCS. Anais... 2007. Disponível em: <http://www.upplay.com.br/restrito/nepso2007/apresentacao.html>. Acesso em 03 jun. de 2014.

ZEICHNER, K. M. Formando professores reflexivos para a educação centrada no aluno: possibilidades e contradições. In: BARBOSA, R. L. L (Org.). Formação de Educadores: desafios e perspectivas. São Paulo: UNESP, 2003. 